\title{
Abstract
}

\section{The Czech Republic: Genetic Counseling in High- Risk Breast/Ovarian Cancer Families}

L. Foretova ${ }^{1}$, E. Machackova ${ }^{2}$, D. Valik ${ }^{1}$ and L. Messiaen ${ }^{2}$

${ }^{I}$ Masaryk Memorial Cancer Institute Brno, Czech Republic

${ }^{2}$ Center of Medical Genetics, University Hospital Gent, Belgium

Genetic counseling of high-risk cancer families was started one and a half years ago in Masaryk Memorial Cancer Institute in Brno, the second largest city in the Czech Republic located in South Moravia. Since that time more than 120 families, mostly with breast/ovarian or colorectal cancers were seen. The inheritance and the possibilities of cancer prevention and surveillance were discussed.

Genetic testing in high-risk breast/ovarian cancer families was offered to 9 families.
Families are currently analyzed at the Center of Medical Genetics, University Hospital, Gent, Belgium. By protein truncation analysis of BRCA1 exon 11 and BRCA2 exon 10 and 11 and heteroduplex analysis of selected exons, truncating mutations were found in 4 out of 9 families. One of these mutations (3875del4 in BRCA1) is frequently seen in the European population and the family would be eligible for haplotype study directed by IARC. Analysis of the remaining exons of BRCA1 and BRCA2 is in progress in the other families.

The genetic surveillance was supported by grants from the agency League Against Cancer Prague, Czech Republic and Terry Fox Foundation. The genetic counseling, and genetic testing in the Czech families will be supported by a grant from the Internal Grant Agency of Ministry of Health of the Czech Republic. 


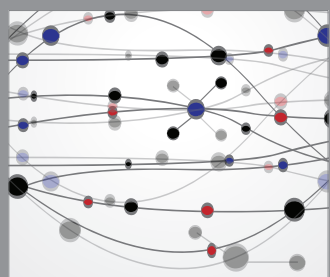

The Scientific World Journal
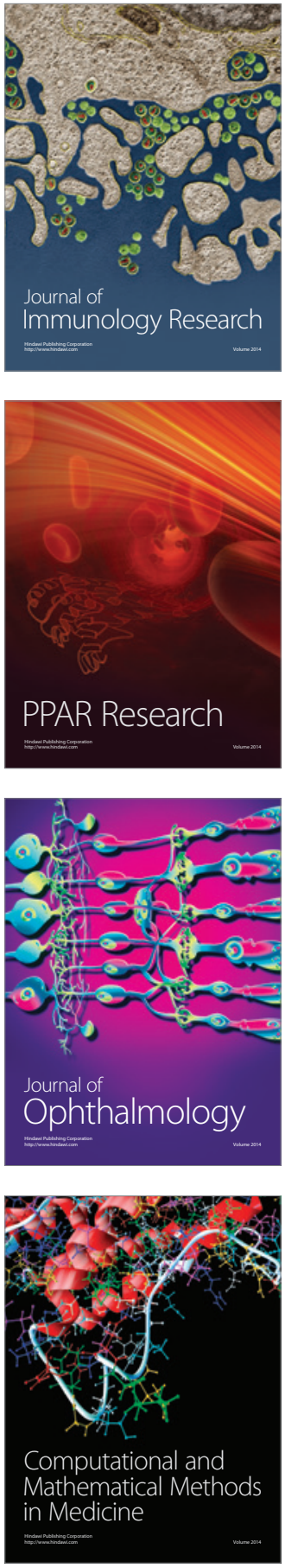

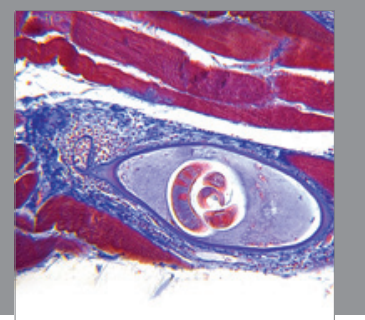

Gastroenterology

Research and Practice
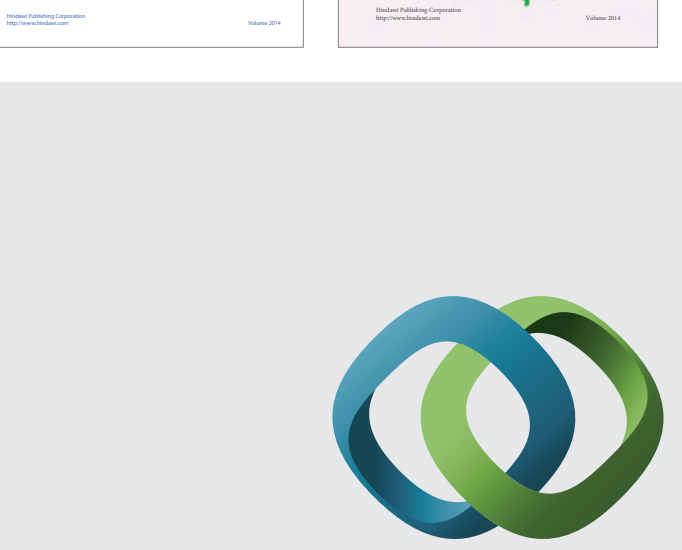

\section{Hindawi}

Submit your manuscripts at

http://www.hindawi.com
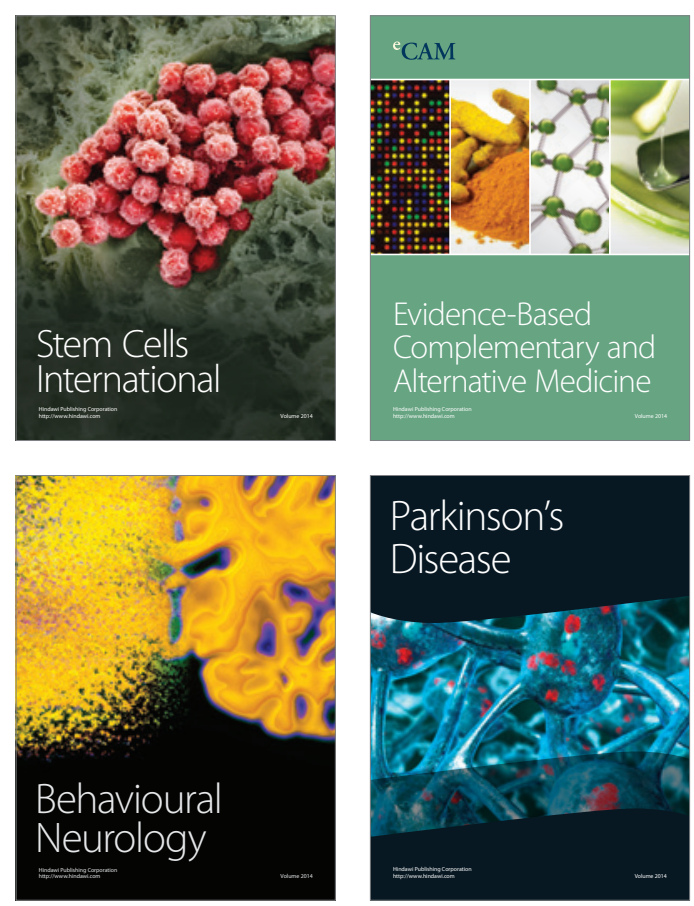

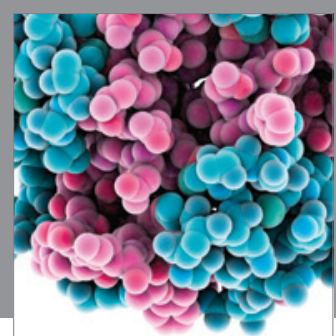

Journal of
Diabetes Research

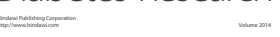

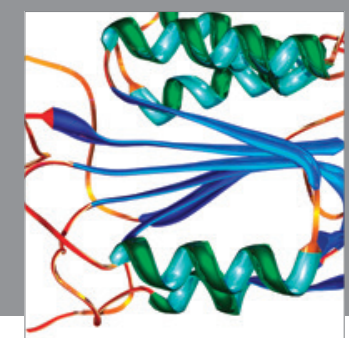

Disease Markers
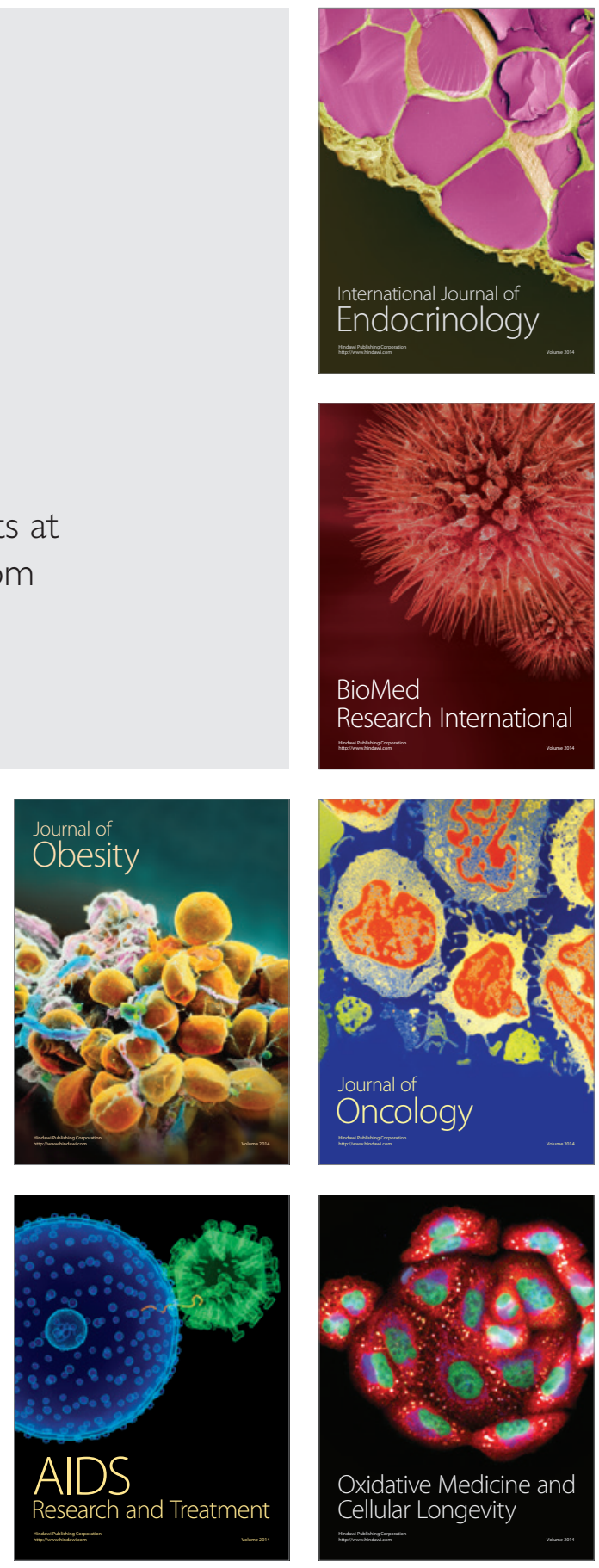